\title{
Fuegos artificiales: la química de las percepciones fugaces
}

FELIX M. GO N I *

Probablemente no haya otro espectáculo que, como los fuegos artificiales, atraiga y seduzca por igual a grandes y pequenos, mujeres y hombres, sin distinción de raza, nivel cultural, ideas políticas o religiosas. Un ramillete de cohetes de brillantes colores o una cascada de chispas plateadas van a impresionar siempre a los espectadores más variados, con la especial seducción que ejerce en nostros todo lo que es fugaz e irrepetible. La pirotecnia es una actividad típicamente artesanal, como la cerámica, o la cocina, y difícilmente podrá ser

mecanizada sin perder algunas de sus virtudes más sobresalientes. Esto no quiere decir, en ningún caso, que las técnicas tradicionales no puedan ser interpretadas de acuerdo con los paradigmas científicos. Esta actitud es incluso imprescindible si se quiere ayudar a los pirotécnicos, 0 a los otros artesanos, a trabajar con mayor calidad y seguridad utilizando los datos de la ciencia, sin por ello alterar lo más mínimo el carácter artesanal de su labor. La tradición que no cambia, muere, y esto lo han demostrado en la práctica los "fogueteiros" portugueses y de otros países, siempre atentos a ofrecer a su público cuantos efectos nuevos Ilegan a conocer. En este artículo repasaremos brevemente algunos aspectos históricos de la pirotecnia y describiremos ciertas técnicas básicas de fabricación, examinando más despacio los principios físico-químicos que subyacen en el arte de la pirotecnia.

\section{HISTORIA}

Dejando aparte antecedentes remotos y mal documentados (como el fuego griego) la pirotecnia tal y como hoy la entendemos nace con el descubrimiento de la pólvora negra y éste se produce, según documentación recientemente publicada por
J. Needham, en China, en el siglo IX de nuestra era, bajo la dinastía Thang, por uno o varios alquimistas desconocidos. Sin embargo, sólo en el siglo XII encontramos en fuentes chinas descripciones de piezas inconfundibles de pirotecnia festiva. Los conocimientos pirotécnicos se transmiten a Occidente durante los siglos XIII y XIV, aparentemente por medio de los árabes. El "Tratado de Caballería y Estratagemas Bélicas" de alRammah (h. 1280) es la primera fuente occidental con descripción detallada de la pólvora y sus aplicaciones, en este caso bélicas. El fraile inglés Roger Bacon (1219-1292?), que dejó escrita en clave la composición de la pólvora, puede haberla conocido de fuentes chinas, directas o indirectas. También correspondería a esta época el supuesto franciscano de Friburgo Berthold Schwartz, a quien se atribuye la invención de la artillería, pero la crítica actual discute la existencia real de este personaje.

La pirotecnia festiva, los fuegos artificiales, hacen su aparición en Europa, en la Italia de fines del quattrocento. Florencia parece haber sido el centro de esta actividad, que conoció un gran auge durante el siglo XVI, con espectáculos de fuegos artificiales ofrecidos frecuentemente en fiestas cívicas o religiosas y, sobre todo, el día de San Pedro y San Pablo (29 de junio). A partir de Italia, los fuegos artificiales se expanden con rapidez por toda Europa, de modo que en lugares relativamente alejados como Inglaterra ya hay espectáculos documentados en 1572. En Europa se van distinguiendo, sobre todo en el siglo XVII, dos estilos pirotécnicos, el meridional, con base en Florencia y Bolonia, y el septentrional, que irradiaba a partir de Nuremberg. La diferencia fundamental es que en el Norte los fuegos se ofrecen por sí solos, mientras que en el Sur las piezas pirotécnicas adornan una gran estructura arquitectónica (la "máquina"), que se ofrece a la curiosidad del público durante días o semanas, y que en la noche final es iluminada por los fuegos de artificio. Quizá sea éste el origen de la expre- sión espanola "castillo" para referirse a una sesión de fuegos artificiales. Las "máquinas" han pervivido, en formas más o menos evolucionadas, hasta bien entrado el siglo XX.

En el siglo XIX se produce en la pirotecnia, y precisamente en Francia, la "revolución del color". En efecto, hasta entonces los únicos efectos de color factibles en pirotecnia eran la gama de los dorados y plateados, que se obtenían con pólvora, carbón vegetal y limadura de hierro, únicos componentes de aquellas mezclas pirotécnicas. Los colores, tal y como hoy los conocemos, sólo son posibles con la aparición del clorato de potasio, obtenido por vez primera por Berthollet en 1786, y utilizado en pirotecnia festiva a partir de 1830 . Los primeros tratados que contienen fórmulas para composiciones coloreadas son los de C.F. Ruggieri (1845) y P. Teissier (1859). Al mismo tiempo, con la disponibilidad del ácido pícrico, aparecen los efectos de "silbatos". Por fin, el descubrimiento $y$ obtención industrial del magnesio (1865) y del aluminio (1894) permiten dar a los fuegos artificiales una luminosidad incomparable. Sin duda, el extraordinario protagonismo de Francia en los avances de la pirotecnia en el siglo XIX es consecuencia directa del espíritu de la Ilustración, que en la centuria anterior tanto había impulsado las "artes aplicadas".

El caso de la historia de los fuegos artificiales en Japón merece tratamiento aparte por su curiosidad. A pesar de la cercanía geográfica a China, Japón recibe los fuegos artificiales, junto con la pólvora y las armas de fuego, de comerciantes holandeses o portugueses a principios del siglo XVII. Es decir, la polvora ha hecho un larguísimo viaje del lejano Oriente a Europa occidental y vuelta, a través de Arabia, a lo largo de unos cuatrocientos anos. El primer espectáculo del que tenemos noticia en Japón tuvo lugar en 1613, organizado por un emisario del rey Jacobo I de Inglaterra. Poco después comienza la producción de fuegos artificiales en Japón: hacía 1620 se funda la firma Marutamaya, hoy la más im- 
portante del país, que ha estado ininterrumpidamente en manos de la familia Ogatsu. En 1733, con ocasión de un funeral budista por las víctimas de una epidemia de cólera, comienza la serie de disparos en el río Ryogoku, que se han celebrado anualmente hasta 1963. El clorato de potasa y los colores se introducen en la pirotecnia japonesa hacia 1880 . En la actualidad, Japón exporta productos pirotécnicos de calidad a todo el mundo, incluída Europa Occidental, en lo que es el segundo periplo de la pólvora en dirección al Oeste, a los trescientos anos de su llegada al archipiélago nipón.

En el siglo XX, la pirotecnia presenta características comunes a casi todas las actividades eminentemente sociales: los espectáculos atraen a grandes masas de espectadores, y esto hace que los fuegos terrestres desaparezcan en favor de los fuegos aéreos, que pueden ser vistos a gran distancia y por una gran cantidad de público: además, la información y el comercio de artículos de pirotecnia se internacionalizan, de manera que los grandes productores (China y, a distancia, Japón, Espana e Italia) invaden todos los mercados, con el consiguiente cierre de pequenos talleres y pérdida de especialidades locales; los polímeros revolucionan la técnica con productos como el cloruro de polivinilo que sustituyen al tradicional clorato y al más moderno perclorato de potasa como dadores de cloro en las reacciones pirotécnicas (ver más abajo), así como la crucial sustitución de la cartuchería de papel y cartón por cartuchos de plástico, que han abaratado considerablemente los productos; en fin, el disparo eléctrico o electrónico de las colecciones, a menudo controlado por ordenador $y$, a veces acompanado, con mayor o menor fortuna, por grabaciones musicales (espectáculos piromusicales) han cambiado considerablemente las dimensiones, el ritmo y la espectacularidad de los disparos. Se debe recordar a este respecto, como uno de los grandes espectáculos del siglo, el disparado en 1986 en Nueva York, con ocasión del centenario de la Estatua de la Libertad, con un presupuesto de dos millones de dólares y 40.000 piezas disparadas electrónicamente desde barcazas.

\section{LOS MATERIALES DE LA PIROTECNIA.}

La pirotecnia moderna utiliza una enorme variedad de materiales entre productos químicos puros (p.ej. el ya mencionado perclorato potásico), sustancias naturales (como el aceite de linaza) y productos manufacturados (papel, plástico). Entre ellos destaca, por numerosas razones, la pólvora negra, de la que hablaremos aparte. En cuanto al resto, R. Lancaster (1) distingue hasta diez clases de productos, a saber: (a) agentes oxidantes o dadores de oxígeno, como los nitratos y percloratos; (b) combustibles, o dadores de electrones, como los metales (aluminio, magnesio, titanio) o el azufre: (c) agentes colorantes de la llama, como el sodio para el color amarillo, el estroncio para el rojo, etc.; (d) sustancias que mejoran determinados efectos, como el cloruro de polivinilo, que aumenta la intensidad de ciertos colores; (e) sustancias generadoras de humo, como la lactosa o la sacarosa; (f) agentes aglutinantes, como la goma laca; (g) agentes flematizantes, que reducen la sensibilidad de las mezclas, como la estearina o la vaselina; (h) estabilizantes, que impiden reacciones químicas no deseadas, como el dicromato potásico para estabilizar el magnesio metálico en polvo; (i) sustancias que aceleran o retardan la combustión, como los cloratos o los carbonatos, respectivamente, y (j) aditivos que ayudan a la fabricación, como los lubricantes. Se observará que la clasificación es más técnica que físico-quimica, y el propio Lancaster advierte que puede haber superposiciones. Así, por ejemplo, el magnesio es un combustible y también se utiliza para aumentar la luminosidad de las composiciones coloreadas, el cloruro de polivinilo se usa para intensificar el color, y es también un combustible, etc. Lancaster incluye en su obra (1) 86 materia- les, sin intentar ser exhaustivo, y Shimizu cita en la suya (2) 90 (incluyendo siete clases de papel).

La pólvora negra requiere mención especial tanto por su importancia histórica como por su papel fundamental en los fuegos artificiales. Quizá se trate de la única preparación de la industria química cuya fórmula no ha variado sustancialmente en los últimos cuatrocientos anos, a saber, nitrato potásico, carbón vegetal y azufre en proporciones cercanas a 75: 15 10. La elaboración es también peculiar: la mezcla cuidadosa de estos componentes, finamente pulverizados, da origen a un material combustible, pero que en ningún caso se convierte en explosivo. La preparación de la pólvora requiere una mezcla íntima que, antes de la mecanización, exigia machacar la mezcla con un mortero de madera de unos seis kilogramos de peso, durante seis horas seguidas. La fabricación industrial, hoy ya casi desaparecida por falta de grandes consumidores (ejército, minas) tiene seis etapas según la descripción de T.L. Davis (3): (a) mezcla de los componentes humedecidos, (b) molienda, con molinos de ruedas de piedra de 4 a 5 toneladas métricas, que muelen unos 150 kilogramos de mezcla durante 3 horas a razón de unas 10 revoluciones por minuto, (c) prensado, en una prensa hidráulica, entre placas de aluminio, (d) granulado en el que las "tortas" resultantes del prensado se fragmentan entre dos rodillos, (e) acabado en el que los gránulos se redondean o pulen y se abrillantan haciéndolos rodar en un barril de madera, al tiempo que se secan, y (f) tamizado y separación por tamanos. En pirotecnia se utiliza la pólvora en polvo impalpable tanto como la granulada. A falta de esta pólvora preparada industrialmente, los pirotécnicos la suelen obtener mezclando los componentes en molinos de bolas, cuyos bombos se hacen girar durante varias horas. La mezcla parcialmente molida, lo que se llama el "crudo", se emplea a veces para cargar cohetes. A diferencia de las aplicaciones industriales o militares, las aplicaciones festivas exigen además que la pólvora arda 
con chispas vistosas; por ello es importante el origen del carbón vegetal, que en el sur de Europa suele ser de sarmiento o de pino.

\section{PRINCIPIOS GENERALES DE LA PIROTECNIA}

La espectacularidad de una colección de fuegos artificiales esconde una gran complejidad de fenómenos físicos y químicos. A continuación, haremos una breve revisión de los más importantes.

\section{Principios Físicos}

La combustión está en la base de casi todos los fenómenos de la pirotecnia. Un parámetro importante para la comprensión de la combustión aplicada a los fenómenos es la velocidad de combustión. Para una materia sólida, como un grano de pólvora, se distingue la velocidad de combustión superficial y la velocidad de internamiento; la primera depende del espacio en torno al combustible, hay una distancia óptima, por encima y por debajo de la cual desciende la velocidad de combustión superficial. Por esta razón, en la pólvora en grano, en la que hay una cierta distancia entre un grano y otro, la combustión se propaga más fácilmente que en la pólvora en polvo, en la que esa distancia es necesariamente más pequena. La velocidad de internamiento depende de diversos factores como composición del combustible, densidad del mismo, presión y temperatura. Según la velocidad de combustión superficial se distingue la combustión propiamente dicha (velocidad: milímetros/segundo) como en el caso de las bengalas o humos de colores, la deflagración o explosión (velocidad: metros/segundo) como ocurre con la pólvora negra en un recipiente cerrado, y la detonación (velocidad: más de un kilómetro/segundo) propia de los llamados "altos explosivos": dinamita, TNT, etc. Esta velocidad de combustión es un parámetro físico que se aplica tanto a

\section{Fabricando Cohetes}

El cohete volador, o simplemente cohete, es sin duda la pieza más antigua de fuego aéreo, atestiguada en China ya en el siglo XII de nuestra era. Las dimensiones del cartucho (sin la cana o timón) pueden variar extraordinariamente, desde unos 6 por $40 \mathrm{~mm}$ para fuegos infantiles, hasta 25 por $200 \mathrm{~mm}$ o más en los grandes cohetones gallegos o portugueses (Figura). A estos tamanos extremos corresponden varillas desde $40 \mathrm{~cm}$ hasta 4 metros. Lancaster (1) ha explicado con sencillez y precisión el principio del cohete: el cohete es un motor a reacción. Tras la ignición, la carga propelente produce gases a alta temperatura y la presión, dentro del cartucho, aumenta. El gas escapa por la estrecha abertura (el oído, o venturi) en un extremo del tubo, de modo que se cumple la ley de conservación de la cantidad de movimiento, y el producto "masa del cohete $x$ velocidad del cohete" es igual al producto "masa del gas liberado $\mathrm{x}$ velocidad del gas" en todo momento.

Aunque existen métodos muy diversos de manufactura de cohetes, un procedimiento empleado comúnmente en la Península Ibérica comienza por sujetar el cartucho sobre un soporte que contiene un saliente del diámetro de lo que luego será el oído. Se introduce entonces una carga de barro, que se comprime, para cerrar el tubo por un extremo y formar, al mismo tiempo, el oído. Una vez seco el barro, el cohete está listo para ser cargado, generalmente con pólvora negra o con mezclas de composición similar. Para la carga, el cartucho se sujeta en un soporte que tiene en su centro una "aguja", cuya forma corresponde a la cavidad cónica estrecha (el ánima) que el cohete tiene en el interior de su carga. Esta cavidad permite que tras la ignición tome fuego a la vez una gran cantidad de propelente. La composición propelente se va anadiendo en porciones, y cada porción se comprime con un cilindro que posee un hueco para albergar la aguja. Cuando la columna de composición alcanza la altura de la aguja, el resto de las porciones de carga se comprimen con un cilindro macizo. El cohete se termina con una fina capa de barro, con un pequeno orificio central, para pasar el fuego a la guarnición. Esta se halla contenida en una bolsa de papel o caperuza de plástico que se ajusta a la parte superior del cartucho. La guarnición o remate puede ser variadísima: uno o varios petardos, estrellas de todo tipo, serpentinas, o bengalas con paracaídas. Los pirotécnicos gallegos y portugueses han desarrollado como nadie el arte de los grandes cohetes (foguetões) en los que dos grandes cohetes unidos a una misma cana de bambú de hasta 4 metros suben a gran altura más de un kilogramo de estrellas, o de la guarnición de que se trate. Estas son estas piezas excepcionales, que merecen ser admiradas de una en una y despaciosamente, como producto que son de una artesanía insuperable.

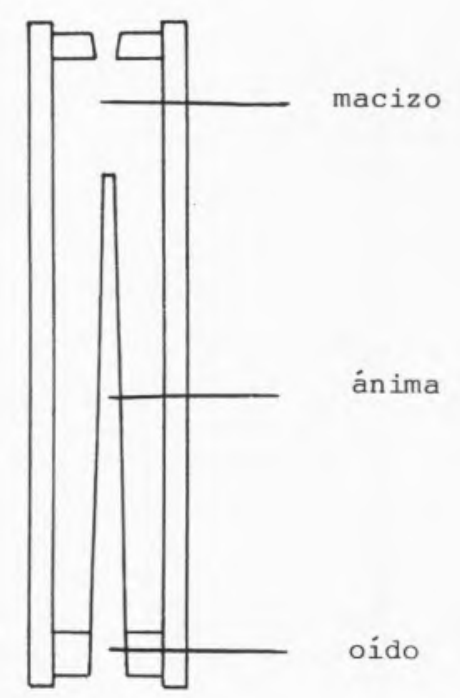

Pie de figura Sección de un cohete cargado [Modificado de Lancaster (1)]. 
sustancias puras (azufre, carbón) como a mezclas (pólvora negra), y no debe ser confundida con el parámetro químico velocidad de reacción que, para una mezcla de sólidos, es mayor cuanto menor es el tamano de la particula. En la práctica, hay que tener en cuenta a la vez los parámetros físicos y los quimicos. Por ejemplo, ya se ha indicado que la pólvora negra sólo deflagra cuando sus componentes, nitrato potásico, azufre y carbón han sido finalmente pulverizados e íntimamente mezclados: esto permite una alta velocidad de reacción. Además, si la pólvora se granula tendremos una alta velocidad de combustión y, por tanto, máxima deflagración. En ocasiones puede convenir lo contrario, como en la fabricación de espoletas o retardos, en los que la pólvora se utiliza en polvo para disminuir la velocidad de propagación superficial y comprimida para aumentar la densidad $y$, por tanto, disminuir la velocidad de internamiento.

La combustión requiere una ignición (la cerilla o el mechero que enciende un cigarro, o una hoguera). Se define el punto de ignición $\left(\mathrm{T}_{\mathrm{b}}\right)$ como la temperature a la que una composición se inflama; desgra- ciadamente $T_{b}$ no es constante, sino que depende de numerosos factores como, por ejemplo, la temperatura ambiente. En términos termodinámicos, la ignición proporciona la energia de activación ( $\left.E_{a}\right)$ que desencadena el proceso. Se distinguen tres mecanismos de ignición, aunque en la práctica es frecuente que actúen los tres a la vez: radiación de calor, como seria la ignición causada por el sol, conducción de calor, que es el más importante en la ignición de la pólvora, y acción mecánica, como ocurre, típicamente, al encender una cerilla. En relación con la ignición hay dos parámetros físicos importantes, que se aplican frecuentemente para estudiar la estabilidad de las mezclas pirotécnicas, y que son la sensibilidad a la fricción y la sensibilidad al choque. Estos dos parámetros suelen aumentar o disminuir en paralelo, aunque no necesariamente ha de ocurrir siempre así. Para el pirotécnico, estas medidas tienen más interés que el punto de ignición, ya que en las mezclas usadas en los fuegos artificiales la estabilidad térmica suele ser mayor que la mecánica. La sensibilidad al choque se mide poniendo una cierta cantidad de producto en una superficie lisa y dejando

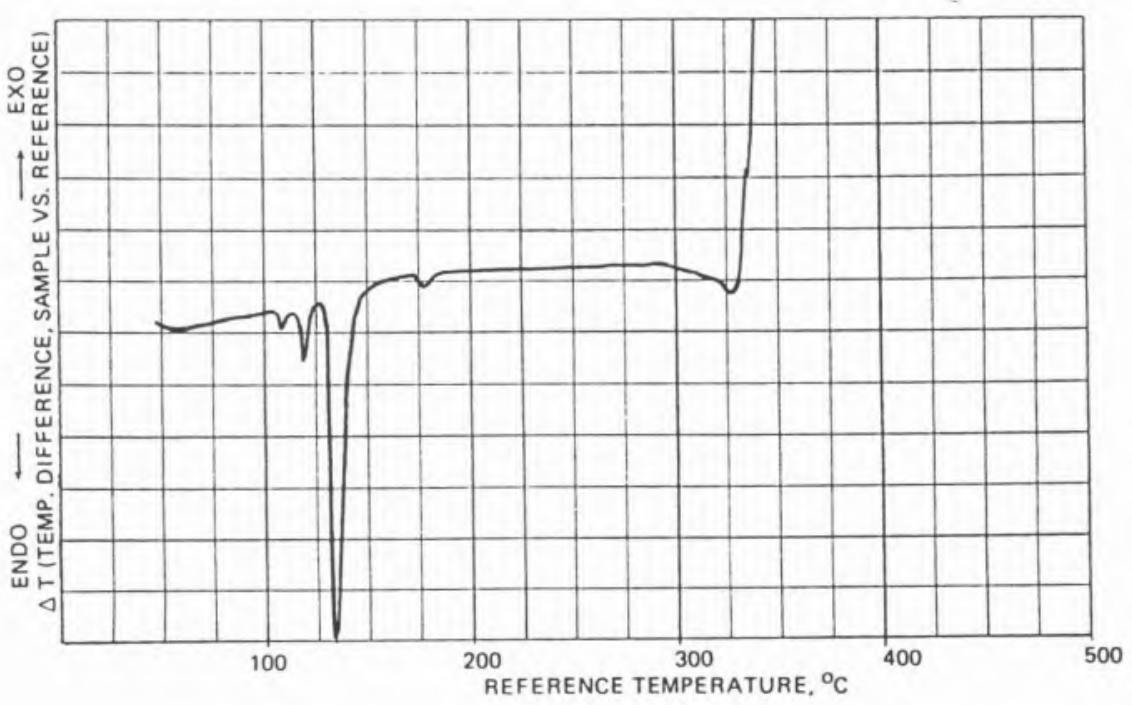

Fig. 1 - Análisis térmico diferencial de una mezcla nitrato potásico/azufre/aluminio. Se distinguen las endotermas del azufre a 105 y $119^{\circ} \mathrm{C}$, y una transición de fase del nitrato potásico hacia $130^{\circ} \mathrm{C}$. Cerca del punto de fusión del $\mathrm{KNO}_{3}\left(334^{\circ} \mathrm{C}\right)$ se observa un gran exoterma, resultado de una deflagración. Tomado de Conkling (4).

caer sobre ella una masa conocida desde alturas crecientes hasta que se produce la ignición. La sensibilidad a la fricción se mide colocando el producto entre dos placas de porcelana, a una de las cuales se aplican fuerzas crecientes hasta producir la ignición. Sustancias particularmente sensibles a la fricción o al choque son el ácido pícrico o la mezcla de clorato potásico y ácido gálico; en el extremo menos sensible de la escala, dentro de las composiciones pirotécnicas, está la pólvora negra. En las condiciones habituales de disparo, el punto de ignición $\left(\mathrm{T}_{\mathrm{b}}\right)$ de casi todas las composiciones pirotécnicas está por debajo de $500^{\circ} \mathrm{C}$, de manera que basta "cebarlas" con pólvora negra para conseguir su rápida ignición. En algunos casos $T_{b}$ es más alto (p.ej. mezclas de nitrato de bario y aluminio atomizado) y, entonces, es necesario recubrir la composición principal con cebos que alcanzan altas temperaturas, como los basados en nitrato potásico y silicio.

La deflagración o explosión es un proceso de combustión rápida que conduce a la dilatación brusca del aire o de otros gases. Normalmente, este proceso rápido produce gases y calor, calor que, a su vez, es el responsable de la dilatación de los gases (Fig. 1). Esta dilatación produce la vibración del aire que conocemos como ruido. Es importante senalar, sin embargo, que la explosión no es siempre como la que acabamos de describir. Hay explosiones sin explosivo, de hecho la mayor explosión conocida en la Tierra fue de este tipo, al penetrar el agua del mar en la caldera del volcán Krakatoa en 1883. El agua se vaporizó por el calor del volcán y el súbito aumento de volumen (18 mililitros de agua líquida corresponden a 22,4 litros de agua en fase de vapor en condiciones normales) originó la tremenda explosión, que llegó a ser oída, días después, en Europa. Otros explosivos, como el acetiluro cuproso, no originan gases en la explosión, sino sólo calor. También hay que considerar que hay explosivos que, en ciertas condiciones, pueden arder liberando energia, sin explotar: es el caso de la 
pólvora cuando arde en un recipiente no confinado. La fuerza de los explosivos es un parámetro relacionado sobre todo con el efecto proyector de los mismos y, por lo tanto, con la cantidad de gas generado en la explosión. Los explosivos se suelen clasificar en tres grupos, (a) impulsores, que contienen oxígeno en su molécula, pueden arder sin explotar y producen gran cantidad de gases (ej. la pólvora negra), (b) primarios, o iniciadores, que explotan por calor o choque, pero no arden (ej. el fulminato de mercurio), y (c) los altos explosivos, poco o nada combustibles, poco sensibles a calor o choque y que, sin embargo, detonan como consecuencia de la explosión de un explosivo primario (ej. dinamita, TNT).

Parte de la energia liberada en los procesos de combustión o explosión se emite como energía luminosa (luz). Este es el principio básico de la utilización de explosivos y mezclas de alta energia en los espectáculos de fuegos artificiales. La luz es un fenómeno electromagnético, de naturaleza, por tanto, a la vez corpuscular y ondulatoria. El parámetro más útil para caracterizar la luz es la longitud de onda (o parámetros relacionados con ella, como la frecuencia). La luz visible contiene longitudes de onda desde unos 380 nanometros (violeta) hasta unos 750 nanometros (rojo). Otro parámetro importante es la amplitud de la radiación, que se corresponde más o menos con la intensidad luminosa. En pirotecnia, es frecuente preparar mezclas cuyos componentes, llevados a una alta temperatura por la combustión, emiten luz. La emisión luminosa puede deberse a uno o varios de estos tres procesos: incandescencia, emisión atómica y emisión molecular. En la incandescencia, o "radiación de cuerpo negro", se emite a la vez luz de todas las longitudes de onda con parecida intensidad, el efecto es una luz dorada (a baja temperatura, 1500 - $2000^{\circ} \mathrm{C}$ ) o blanca (a alta temperatura, $2500-3000^{\circ} \mathrm{C}$ ). Combustibles como la laca o el carbón vegetal (baja $\mathrm{T}$ ), el magnesio o el aluminio (alta T) producen luz sobre todo por incandescencia. La emisión atómica se debe a la relajáción de átomos que previamente han sido excitados por la energia térmica de la combustión. En la práctica de los fuegos artificiales, la emisión atómica sólo tiene interés en el caso del átomo de sodio, que emite una intensisima luz amarilla a 589 nanometros. El resto de los átomos que intervienen en las composiciones pirotécnicas emiten por si solos radiaciones de débil intensidad, pero no así cuando están combinados formando determinadas moléculas inestables. Asi, el estroncio (Sr) atómico da una débil luz azul, pero la molécula del cloruro de estroncio $\mathrm{SrCl}$, que sólo existe a altas temperaturas, emite un color rojo muy intenso. Otros ejemplos de emisión molecular son el cloruro de bario $\mathrm{BaCl}$ (luz verde) o el de cobre $\mathrm{CuCl}$ (luz azul). Todas estas son moléculas inestables que sólo se forman en condiciones de combustión. Las mezclas pirotécnicas de color tienen como finalidad obtener estas moléculas que son capaces de originar fenómenos de emisión molecular intensa (Fig. 2).

Desde el punto de vista técnico, una fuente luminosa (p.ej. una bengala de pirotecnia) se caracteriza por su brillo, tono y pureza. La brillan-

\section{Fabricando Estrellas de Colores}

Las estrellas de composición coloreada son las responsables de los brillantes colores de los fuegos artificiales aéreos. Hay varios métodos de preparación de estrellas, en el más sencillo se humedece la composición con agua o alcohol, se extiende en una superficie lisa y se corta en cuadritos con un cuchillo. Las estrellas cúbicas resultantes (de unos milímetros de lado) se recubren de pólvora en polvo fino y se dejan secar. En otras ocasiones, la composición humedecida se introduce y comprime en moldes cilíndricos, dando lugar a las llamadas bombetas; ciertas composiciones exigen ser prensadas en seco a alta presión. Algunas estrellas consisten en tubos de papel rellenos de la composición prensada en seco y cebada con pólvora negra, a veces con su mecha; estas estrellas son laboriosas pero ofrecen resultados espectaculares por su luminosidad y duración. La escuela galaico-portuguesa perfora estas estrellas por un extremo antes de cebarlas, con lo que cada una se convierte en un pequeno cohete borracho, dando lugar al efecto de "estrellas fugaces". Los japoneses han popularizado en todo el mundo las estrellas esféricas o bolas, obtenidas incorporando capas sucesivas de la composición humede- cida sobre un núcleo inerte, típicamente semillas de cereales, en un bombo rodante. Las bolas tienen diámetros desde menos de 10 hasta más de $20 \mathrm{~mm}$, según sus aplicaciones, y las sucesivas capas pueden ser de distinta composición, con lo que se obtienen estrellas que cambian de color.

Algunas composiciones para estrellas coloreadas (de las que se cortan en cubitos) son:

\section{Rojo}

Perclorato potásico $\quad 70$

Carbonato de estroncio $\quad 15$

Resina acaroides 9

Carbón malla 150

Dextrina

$\begin{array}{lr}\text { Amarillo } & \\ \text { Perclorato potásico } & 70 \\ \text { Oxalato sódico } & 14 \\ \text { Resina acaroides } & 6 \\ \text { Shellac malla 80 } & 6 \\ \text { Dextrina } & 4\end{array}$

Verde

Clorato básico $\quad 72$

Resina acaroides $\quad 12$

Carbón malla 150

Dextrina 4

Carbonato básico 4 
tez es proporcional a la intensidad luminosa, cuya unidad de medida en el SI es la candela (cd). El tono se refiere a la longitud de onda máxima de la emisión, expresada en las unidades correspondientes (ej. nanometros). La pureza viene indicada por la anchura de la banda espectral que contribuye

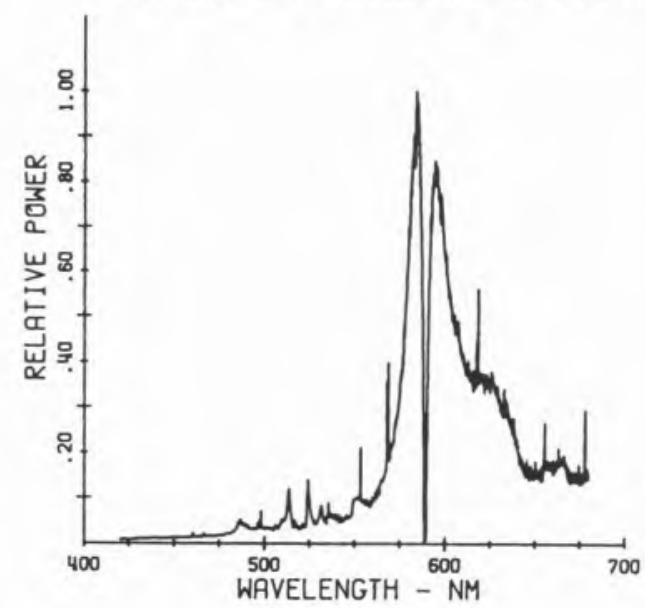

Fig. 2 - Espectro de emisión de una bengala amarilla. La principal especie emisora es el sodio atómico, centrada hacia $589 \mathrm{~nm}$. Se observa, además, una banda ancha y continua de emisión de incandescencia ("cuerpo negro"). Tomado de Webster (5).

al efecto luminoso (en la práctica anchura de la banda a la mitad de su altura), y se mide también en nanometros. Idealmente, una llama coloreada debe tener a la vez brillo y pureza (p.ej. un verde muy luminoso y muy intenso). En la práctica, lo que aumenta el brillo es generalmente incandescencia, o sea, una emisión de amplio espectro, que contamina la pureza, por lo que se debe llegar a un compromiso entre brillo y pureza para cada tonalidad de color deseada.

\section{Principios Quimicos}

También desde el punto de vista químico debemos comenzar por considerar la combustión. Al tratarse de un proceso de oxidorreducción, la combustión necesita un agente reductor, que es el combustible (ver el apartado Los materiales de la pirotecnia) y de un agente oxidante. En las combustiones domésticas (el gas de la cocina, el carbón de la barba- coa) el agente oxidante es el oxígeno de la atmósfera. En las mezclas pirotécnicas, el oxígeno atmosférico no basta, y se incluye una fuente de oxigeno o agente oxidante, como el nitrato potásico $\left(\mathrm{KNO}_{3}\right)$ en la pólvora negra, o el perclorato potásico $\left(\mathrm{KClO}_{4}\right)$ en numerosas formulaciones de color. En la combustión, el fenómeno básico es la transferencia de electrones del combustible (reductor) al oxígeno (oxidante), que se acompana de la liberación de energia en forma de luz y calor. En todas las composiciones pirotécnicas nos encontramos con, al menos, un oxidante y un combustible/reductor. Un caso sencillo es la composición para "truenos" o petardos que consiste sólo en perclorato potásico y aluminio, el primero oxidante, fuente de oxigeno y pozo de electrones, y lo contrario el segundo, reductor. dador de electrones, combustible. Las composiciones coloreadas suelen ser algo más complejas, por las razones ya mencionadas. Una composición para estrellas amarillas, que arde a relativamente baja temperatura, contiene perclorato potásico (oxidante), oxalato sódico (proporciona el elemento colorante, sodio), resina acaroides, goma laca y dextrina (los tres últimos combustibles de baja temperatura y aglutinantes). Una composición roja de alta temperatura contiene nitrato de estroncio (oxidante y fuente de elemento colorante, estroncio), magnesio (combustible de alta temperatura y emisor de luz por incandescencia) y cloruro de polivinilo (combustible y dador de cloro para la formación del emisor molecular $\mathrm{SrCl}$ ). En una composición de este tipo se recomienda mantener un exceso de combustible (balance de oxigeno negativo) que mantenga desplazada hacia la izquierda la reacción de oxidación del SrCl: $2 \mathrm{SrCl}+\mathrm{O}_{2} \rightleftarrows 2 \mathrm{SrO}+\mathrm{Cl}_{2}$.

Pero el quimico pirotécnico se encuentra con frecuencia con reacciones secundarias o colaterales que, en la práctica, son tan importantes como la combustión. Un ejemplo notorio es la reactividad de las mezclas de clorato de potasio con azufre, que tantas vidas humanas ha costado. Parece que la inestabilidad de estas mezclas se debe a que el aire oxida la superficie de las particulas de azufre originando ácido sulfuroso, y que éste reacciona inmediatamente con más azufre dando lugar a ácidos politiónicos $\left(\mathrm{H}_{2} \mathrm{~S}_{\mathrm{n}} \mathrm{O}_{6}\right)$. A su vez, éstos se pueden descomponer dando ácido sulfúrico y dióxido de azufre $\left(\mathrm{SO}_{2}\right)$.

$$
\mathrm{H}_{2} \mathrm{~S}_{\mathrm{n}} \mathrm{O}_{6} \rightarrow \mathrm{H}_{2} \mathrm{SO}_{4}+\mathrm{SO}_{2}+(\mathrm{n}-2) \mathrm{S}
$$

El $\mathrm{SO}_{2}$ reacciona con el clorato en presencia de humedad para dar dióxido de cloro $\left(\mathrm{ClO}_{2}\right)$, muy explosivo.

Estas reacciones se pueden desencadenar por el calor, incluído el de la luz solar, la fricción y el impacto, así como por impurezas de los reactivos (p.ej. clorato cálcico, muy inestable). Muchos de estos problemas se evitan sustituyendo el clorato por el perclorato de potasio como oxidante. Al parecer las mezclas a base de perclorato son sólo un poco menos sensibles a la fricción y al choque que las basadas en clorato, pero son más estables químicamente.

Toda una serie de reacciones indeseadas se deben a la humedad. Este problema es tanto más importante cuanto que los fuegos artificiales deben ser susceptibles de almacenamiento durante largos períodos de tiempo y en condiciones muy variadas. Un caso tipico de mezclas sensibles a la humedad es el de aquéllas que contienen magnesio y nitratos, frecuentemente utilizadas para obtener llamas rojas o verdes muy luminosas. El magnesio reacciona con el agua, de manera exotérmica, liberando hidróxido magnésico e hidrógeno, y éste reacciona con el nitrato, para dar amoníaco con lo que, tanto el combustible como el oxidante, quedan alterados.

$$
\begin{aligned}
8 \mathrm{Mg}+16 \mathrm{H}_{2} \mathrm{O} & \rightarrow 8 \mathrm{Mg}(\mathrm{OH})_{2}+8 \mathrm{H}_{2} \\
\mathrm{Ba}\left(\mathrm{NO}_{3}\right)_{2}+8 & \mathrm{H}_{2} \rightarrow \mathrm{Ba}(\mathrm{OH})_{2}+4 \mathrm{H}_{2} \mathrm{O} \\
+ & 2 \mathrm{NH}_{3}
\end{aligned}
$$

Para evitar estos problemas, el magnesio se trata previamente con aceite de linaza o algún tipo de resina que forma una fina pelicula en 
torno a las partículas, aislándolas de la humedad. El aluminio es más estable que el magnesio con respecto a la humedad, porque su superficie se recubre de una capa de óxido que proteje el resto de la particula. En los últimos anos, se ha introducido en este tipo de mezclas el titanio, que no se afecta por la humedad, o aleaciones de magnesio y aluminio, que se estabilizan espontáneamente al recubrirse de óxido de aluminio. Los problemas causados por la humedad obligan también a evitar en las mezclas pirotécnicas las sustancias higroscópicas, o sea, que absorben agua del ambiente. Así, por ejemplo, no sólo el clorato sódico es desaconsejable, por higroscópico, sino que también se debe evitar mezclas, por ejemplo, de clorato potásico y oxalato sódico que, en presencia de agua, pueden dar origen a la sal citada, a través de una doble descomposición. Otra importante reacción de doble descomposición es la que puede ocurrir al mezclar clorato potásico con sales de amonio (el perclorato amónico se utiliza para obtener luces azules), pues se origina clorato amónico, altamente explosivo. Naturalmente, esto no ocurre si se utiliza perclorato potásico en vez de clorato.

A menudo es importante controlar la acidez o basicidad que puedan aparecer en una mezcla en presencia de humedad. Así, en composiciones con cloratos, p.ej. de bario, que tienden a descomponerse en presencia de ácidos, conviene anadir un pequeno porcentaje del carbonato correspondiente, que contrarresta la acidez. Por el contrario, la reacción del aluminio con agua se facilita en medio básico, y puede ser neutralizada con una pequena proporción de ácido bórico.

Otro interesante fenómeno quimico de aplicación a la pirotecnia es el de las reacciones oscilantes, combustiones en las que el proceso va siendo progresivamente más rápido hasta que se produce, en el seno de la mezcla, una microdeflagración. Esta pequenisima explosión deja un rescoldo, que reaviva la combustión, iniciándose un nuevo ciclo. En la práctica, se utilizan diversas mezclas, como perclorato po-

\section{La Pirotecnia Iberica}

La Península Ibérica es quizá el lugar del mundo donde conviven en menor espacio tradiciones pirotécnicas más distintas. En efecto, se pueden distinguir tres escuelas o tradiciones, que curiosamente corresponden a las tres franjas linguísticas más importantes: la galaico-portuguesa, la central y la catalano-valenciana. La primera, con centros en Galicia y Norte de Portugal (Viana do Castelo y provincia del Miño) ha desarrollado al máximo la técnica de los cohetes voladores, como se ha dicho al describir estas piezas. Los grandes cohetones se disparan de uno en uno, alternando con ramilletes de cohetes más pequenos, con efectos a juego con los de los grandes. A diferencia de la carcasa, que es necesariamente ruidosa por las cargas de ascensión y de apertura, el espectáculo de voladores es de por sí completamente silencioso, de manera que el pirotécnico puede anadir a voluntad y, generalmente en pequenas dosis, composiciones de trueno, creanso así ritmos variados. El espectáculo de los callados cohetones, liberando las brillantes estrellas fugaces, que cubren el cielo de color en completo silencio, es una imagen fantasmagórica que cuadra bien con las historias de meigas del folklore local. Desgraciadamente, este tipo de fuego es también víctima de la tendencia universal a homogeneizar las costumbres. Actúa en su contra el alto costo en mano de obra cualificada y el resquemor con que se ve la caída de canas y cartuchos encendidos en tierras no banadas por el orvallo, lo que lo hace no exportable. Entre unas cosas y otras, es hoy más fácil ver en las fiestas gallegas una buena carcasa china que un buen cohetón local. Para compensar, Rocha y otros artesanos gallegos venden en toda Espana sus famosos cohetones de paracaídas con gusanos de color. No debemos olvidar en este apartado el inimitable virtuosismo que en el terreno del fuego terrestre ("fogo preso") han desarrollado los Fernandes y los Silvas en Portugal. En la costa mediterránea $y$, justamente en la parte catalano-parlante, ha florecido desde tiempo inmemorial el gusto y la habilidad por un tipo de pirotecnia caracterizado por la ruidosidad y el barroquismo de sus formas, junto con una notoria capacidad para incorporar novedades desarrolladas en otros lugares. En la actualidad, parece que no hay pieza o efecto pirotécnico en el mundo que no se fabrique con calidad y dispare con abundancia en Valencia, la capital reconocida de la pirotecnia levantina. Estos artesanos fabrican por igual el cohete, la candela y la carcasa, y ésta en sus formas cilíndrica o esférica, todo ello con una relación calidad-precio que les convierte en líderes mundiales, junto a Japón, del comercio de fuegos artificiales de calidad.

En sus espectáculos se combinan todos los elementos citados de manera que, por ejemplo, las candelas romanas, carcasas de pequeno calibre y carcasas de grueso calibre, disparadas a la vez, llenan el escenario aéreo desde el suelo hasta la máxima altura. El disparo de un "castillo" o colección de fuegos artificiales por los miembros de las dinastías Caballer o Brunchú es, sin duda, una de las experienclas más singulares de la pirotecnia mundial. Junto a estas dos distinguidísimas tradiciones, occidental y levantina, la zona central, correspondiente a las lenguas vasca y castellana, resulta algo deslucida, con un estilo ecléctico influenciado por las otras dos. 
tásico/salicilato potásico, en las que el ciclo se repite unas 2600 veces por segundo. El resultado auditivo es el de un silbido agudo. Otras reacciones oscilantes, de ciclo mucho más lento (24 veces por segundo), se aplican a composiciones coloreadas para producir efectos de luz intermitente.

Como resumen y aplicación de los principios químicos aqui mencionados, podemos indicar seguidamente algunas composiciones usuales para colores. Los rojos se confeccionan habitualmente con perclorato potásico y carbonato de estroncio, mientras que para el verde se utiliza el nitrato de bario. El azul es más complicado, y requiere mantener una baja temperatura de llama, pues el $\mathrm{CuCl}$ es inestable por encima de $1200^{\circ} \mathrm{C}$; el agente colorante más común es el llamado verde de París (acetoarseniuro de cobre), aunque se obtienen efectos excelentes con perclorato amónico y carbonato básico de cobre, siempre con perclorato potásico como oxidante. El amarillo se consigue con oxalato sódico (higroscópico) o, mejor, con criolita, un fluoruro natural de aluminio y sodio. Los Colores blancos y plateados resultan de la combustión del aluminio o del titanio, mientras que los dorados se obtienen, en general, con carbón vegetal.

Desde el punto de vista de las reacciones indeseadas y la seguridad, se puede decir que nunca se deben mezclar cloratos con azufre o sulfuros, con sales de amonio, con fósforo, picratos o metales pulverizados, y que las mezclas de cloratos y ácido gálico son muy peligrosas. Tampoco se deben mezclar cloratos y oxalato, por el problema de la humedad, ya mencionado. Las mezclas con clorato son muy sensibles a la fricción y al choque. Por su parte, el perclorato potásico no se debe mez clar con azufre o sulfuros, con fósforo, ni con picratos. Las mezclas de perclorato y metales pulverizados son peligrosas. Las mezclas que contienen perclorato son también muy sensibles a la fricción y al choque.

\section{* Departamento de Bioquímica, Universidad del País Vasco, Aptdo, 644, 48080}

\section{BIBLIOGRAFIA}

1. R. Lancaster. Fireworks, Principles and Practice (2nd edition). Chemical Publishing Co., Nueva York, 1992.

2. T. Shimizu. Fireworks. The Art, Science and Technique. Maruzen, Tokyo, 1981.

3. T.L. Davis. The Chemistry of Powder and Explosives, John Wiley and Sons, Inc., New York, 1941.

4. I.A. Conkling, Chemistry of Pyrotechnics. Marcel Dekker. New York, 1985.

5. H. A. Webster III. Visible Spectra of Santandard Navy Colored Flares. En: Proceedings, Explosives and Pyrotechnics Applications Section, American Defense Preparedness Association, Fort Worth, Texas, 1983.

EQUIPAMENTOS DE ANÁLISE E ENSAIO, LDA,

